\title{
ORIGNAL ARTICLE
}

\section{ASSESSMENT AND COMPARISON OF GALLBLADDER MASS BY SONOGRAPHY AND HISTOPATHOLOGY}

\author{
J. S. Sikarwar' ${ }^{1}$ Rashmi Singh ${ }^{2}$, Vrashbhan Ahirwar³, Harish Bhujade ${ }^{4}$, Shilpi Muchhoria ${ }^{5}$
}

\section{HOW TO CITE THIS ARTICLE:}

J. S. Sikarwar, Rashmi Singh, Vrashbhan Ahirwar, Harish Bhujade, Shilpi Muchhoria. "Assessment and Comparison of Gallbladder Mass by Sonography and Histopathology". Journal of Evolution of Medical and Dental Sciences 2014; Vol. 3, Issue 09, March 03; Page: 2076-2086, DOI: 10.14260/jemds/2014/2106

ABSTRACT: AIMS \& OBJECTIVES: To find out prevalence of gallbladder mass among the patients of gallbladder pathology \& define morphological feature of gall bladder masses using real time gray scale ultrasonography and color Doppler flow imaging \& power Doppler imaging to find out prevalence of gall stones among the patients of gall bladder mass. MATERIAL AND METHOD: 10424 patients were evaluated for gall bladder pathology with grey scale ultrasonography in between 1.10.12 to 30.09.2013 in Radiodiagnosis department of G.R.M.C. RESULT: 54 patients out of 10424 i.e. $0.5 \%$ were found to have gall bladder mass lesion. Among these $79.5 \%$ (43) of patients had gall bladder carcinoma, 9.3\% (5) had gall bladder polyp, 87.4\% (4) had mucocele of gall bladder 1.9\% (1) had porcelain gall bladder and 1.9\% (1) had gall bladder metastasis. The youngest patient in our study was 12 years old male presented with mucocele. Oldest patient in our study was 68 years old female presented with gallbladder carcinoma.7\% of overall gall bladder mass lesion were encountered in females showing clear female preponderance. Gall Stone embedded in $70 \%$ of gall bladder mass. CONCLUSION: J.A. group of hospital and G.R. Medical College, Gwalior serve a good proportion of population of M.P. and adjoining area of U.P. and Rajasthan which is endemic for gall bladder pathology. The present study concludes that ultrasonography is a powerful readily available and cost effective tool in the diagnosis of gall bladder pathology.

KEYWORDS: Ultrasound of gallbladder, carcinoma of gallbladder, gall bladder stone.

INTRODUCTION: Gall bladder mass lesions include a spectrum of disease entities those had remained a major cause of human morbidity and mortality since the ancient times. Prominent entities among these are carcinoma of the gallbladder, mucocele, polyp, porcelain gallbladder and parasitic infestations. Carcinoma of gallbladder dominates this list because of its comparative high prevalence and lethal nature.

Carcinoma of the gallbladder is the commonest biliary tract malignancy with poor prognosis. It ranks fifth in incidence of gastrointestinal carcinomas and represents about three fourths of extrahepatic biliary tract carcinoma. It accounts for approximately 6600 deaths per year in United States alone ${ }^{1}$.

There is considerable geographical variation in the incidence of carcinoma of the gallbladder. It is one of the most frequent neoplasm in Chile, and it is the leading cause of cancer deaths in females ${ }^{2}$. High prevalence rates are also reported from Israel, Mexico and Bolivia ${ }^{3}$. Intermediate incidence is seen in Japan and India 4 . Lowest incidence were found in Nigeria and Singapore. This geographical difference suggests the role of environmental, ethnic and genetic factors in the etiopathogenesis of this dreaded disease ${ }^{5}$. Carcinoma of the gallbladder is a disease of elderly women. This disease is more common in 4th to 6th decade of life in India ${ }^{6}$. Parity, younger age at menarche and early age at first pregnancy have been shown to increase the risk of gallbladder cancer in female 7 . 


\section{ORIGNAL ARTICLE}

The exact cause of gallbladder cancer is not known, however various predisposing factors have been proposed in its pathogenesis. Among the predisposing factors for carcinoma of the gallbladder, cholelithiasis is most frequent. Cholelithiasis is found in 3/4th of the patient with carcinoma of the gallbladder.

The epidemiology of carcinoma of the gallbladder runs parallel to that of cholelithiasis, both show a high female to male ratio, an increasing incidence with age and an identical variation among ethnic group. It has been suggested that chronic trauma and inflammation of gallbladder mucosa, caused by presence of gallstones induce epithelial dysplasia which may predispose to carcinoma ${ }^{1}$. The size of calculi was found to correlate with probability of developing gallbladder carcinoma ${ }^{5}$. Carcinoma of the gallbladder is found only in $1-3 \%$ of patients with cholelithiasis and $25 \%$ cases of gallbladder cancer do not have documented cholelithiasis ${ }^{1}$.

An association between typhoid carrier state and hepatobiliary cancer particularly that of carcinoma of the gallbladder has been noted ${ }^{8}$. In enteric fever, infection of gallbladder occurs regularly9. Typhoid and paratyphoid bacilli reside in the gallbladder of the carriers and are excreted through the bile duct. The risk of gallbladder cancer in typhoid carriers is 6 times higher than the risk for general population. ${ }^{10}$ The lifetime risk of gallbladder cancer was found to be $6 \%$ in carriers.

Calcification of gallbladder or porcelain gallbladder is an important risk for carcinoma of the gallbladder accounting for $12-61 \%{ }^{1}$ Xanthogranulomatous cholecystitis is a variant of chronic cholecystitis and also present as a risk factor. ${ }^{11}$ But the association may be coincidental. Factors responsible for benign gallbladder diseases such as age, hormonal and dietary factors also seem to be associated with gallbladder carcinogenesis.

Bile acids are tumor promoters and co-mutagens. Increased degradation of primary bile acids to secondary bite acids in the gallbladder bile has been observed in patients with carcinoma of the gallbladder. Marked increased in the secondary bile acids and raised biliary deoxycholate have been observed in gallbladder bile in the patients with gallbladder carcinoma ${ }^{12}$. Combination of bile stasis and bacterial infection of biliary system producing altered bile salts were thought to be related to carcinogenesis. ${ }^{13}$ Numerous other factors in etiopathogenesis of the carcinoma of the gallbladder have been proposed and investigated including biliary cyst malignancy transformation of benign neoplasm, anomalous junction of pancreaticobiliary duct system, ulcerative colitis and cholecystoenteric fistula 1 .

As only 65 to $70 \%$ of cases of gallbladder are associated with cholelithiasis so there must be some other risk factors for 25 to $30 \%$. Typhoid carrier stage may be important risk factor as it causes formation of secondary bile acids in gallbladder which is carcinogenic. The present study is based on this hypothesis.

\section{AIMS \& OBJECTIVES}

- To find out the incidence of gallbladder pathology among the patients of Jayarogya Hospital.

- To find out prevalence of Gallbladder Mass among the patients of gallbladder pathology.

- To find out prevalence of gallstones among the patients of Gallbladder mass.

- To find out the prevalence of other sonographic finding among the patients of gall bladder masses.

- To compare the relative occurrence of these findings among the patients. 


\section{ORIGNAL ARTICLE}

MATERIAL AND METHODS: The present study will be a cross sectional observational study to be carried out in the OPD/IPD of Jayarogya Hospital, Gwalior \& G.R. Medical College, Gwalior. This will includes the patients coming to Radiology Department for Ultrasonography 1.10.12 to 30.09.2013.

OBSERVATIONS: The present study entitled "Ultrasonographic evaluation of patients of gallbladder pathology" attending Jayarogya Hospital, Gwalior for the duration of one year.

In our study a total of 10424 patients were evaluated with grey scale ultrasonography for gall bladder pathology.

Among these 54 patients of gallbladder mass lesion were evaluated with grey scale ultrasonography, color, duplex and power Doppler Role of the above modalities was studied in defining the characteristics and extent of the lesions. The imaging findings were correlated with surgical/ histopathological/FNAC findings.

\begin{tabular}{|c|c|c|}
\hline Lesion & No. of Cases & \%age \\
\hline Gallbladder Carcinoma & 43 & 79.5 \\
\hline Gallbladder polyp & 5 & 9.3 \\
\hline Mucocele & 4 & 7.4 \\
\hline Porcelain gallbladder & 1 & 1.9 \\
\hline Metastasis & 1 & 1.9 \\
\hline Total & 54 & 100 \\
\hline
\end{tabular}

Carcinoma gallbladder was the commonest type $(79.5 \%)$ of mass lesion in gallbladder encountered in our study. Metastasis accounted for $(1.9 \%)$ cases. All the benign masses in total accounted for remaining (18.6\%) of gallbladder mass lesions. Gallbladder polyps are most common among the benign lesions accounting for (9.3\%) cases, with mucocele second most common accounting for $(7.4 \%)$ of cases.

\begin{tabular}{|c|c|c|c|c|c|c|c|}
\hline Lesion & $10-20$ & $20-30$ & $30-40$ & $40-50$ & $50-60$ & $60-70$ & Total \\
\hline Gallbladder Carcinoma & - & - & 9 & 12 & 14 & 8 & 43 \\
\hline Gallbladder polyp & - & 1 & 2 & 1 & 1 & - & 5 \\
\hline Mucocele & 1 & - & - & 1 & 2 & - & 4 \\
\hline Porcelain gallbladder & - & - & - & - & 1 & - & 1 \\
\hline Metastasis & - & - & 1 & - & - & - & 1 \\
\hline Total & 1 & 1 & 12 & 14 & 18 & 8 & 54 \\
\hline
\end{tabular}

The youngest patient in our study was 12 year old male presented with mucocele. Oldest patient in our study was 68 year old female presented with gallbladder carcinoma. Maximum numbers of cases of carcinoma GB were encountered in the age group of 50-60 years. No case of gallbladder carcinoma was seen below the age of 32 years. 


\section{ORIGNAL ARTICLE}

Patients above the age of 40 years account for $34 / 43(80 \%)$ cases of gallbladder carcinoma. Only 2 cases are encountered in the age group of 20-30 years, gallbladder polyp and mucocele one case each. Mean age for the benign lesions is less compared to the age for malignant lesions.

\begin{tabular}{|l|c|c|c|}
\hline \multicolumn{1}{|c|}{ Lesion } & Male & Female & Total \\
\hline Gallbladder carcinoma & 10 & 33 & 43 \\
\hline Gallbladder Polyp & 2 & 3 & 5 \\
\hline Mucocele & 1 & 3 & 4 \\
\hline Porcelain gallbladder & - & 1 & 1 \\
\hline Metastasis & - & 1 & 1 \\
\hline \multicolumn{1}{|c|}{ Total } & 23(24\%) & $\mathbf{4 1 ( 7 6 \% )}$ & $\mathbf{5 4}$ \\
\hline
\end{tabular}

TABLE 3: DISTRIBUTION OF CASES ACCORDING TO SEX

***No. inside brackets showing percentage

41 cases $(76 \%)$ of gallbladder mass lesions were encountered in females, showing clear female preponderance, accounting for more than three forth of all cases. In gallbladder carcinoma also, females are accounting for 33/43 (77\%) of cases i.e. more than three fourth cases. 7 out of 10 Benign lesions were encountered in female accounting for $70 \%$ of cases.

\begin{tabular}{|c|c|c|}
\hline \multicolumn{1}{|c|}{ USG Features } & No. of Cases & \%age \\
\hline Poly Paid Mass & 8 & 18.6 \\
• Fundus & 5 & 11.6 \\
- Body & 1 & 2.3 \\
• Neck & 2 & 4.6 \\
\hline Asymmetric thickening of Gallbladder wall & 5 & 11.6 \\
\hline Filling/Replacing Gallbladder & 30 & 69.8 \\
\hline TABLE 4: PRIMARY SONOGRAPHIC FEATURE OF GALLBLADDER CARCINOMA
\end{tabular}

Majority of gallbladder carcinoma presented as a mass filling or replacing the gallbladder accounting for $(70 \%)$ of cases. Second most common presentation is that of polypoid mass (18.6\%). Least common presentation is asymmetrical thickening of gallbladder wall (12\%). GB masses presenting as polypoid lesions are most common in fundus of the gallbladder.

\begin{tabular}{|c|l|c|c|}
\hline S. No. & \multicolumn{1}{|c|}{ Features } & No. of Cases & \%age \\
\hline \multicolumn{3}{|c|}{ COLOR AND DUPLEX DOPPLER } \\
\hline \multirow{4}{*}{1.} & Grading of vascular signal & & \\
& Grade 0, No flow & 3 & 6 \\
& Grade 1 spotty flow* & 10 & 23.3 \\
& Grade 2 Multiple Scattered Flow & 26 & 60.5 \\
& Grade 3 continuous flow** & 4 & 9.3 \\
\hline \multirow{3}{*}{2.} & Duplex Doppler*** & & \\
& Peak systolic velocity > 40 cm/s & 43 & 100 \\
& $<40 \mathrm{~cm} / \mathrm{s}$ & & \\
\hline
\end{tabular}




\section{ORIGNAL ARTICLE}

\begin{tabular}{|c|c|c|c|}
\hline \multicolumn{4}{|c|}{ POWER DOPPLER FEATURES } \\
\hline 1. & $\begin{array}{l}\text { Grading of vascular signal } \\
\text { Grade } 0 \text {, No flow } \\
\text { Grade } 1 \text { spotty flow* } \\
\text { Grade } 2 \text { Multiple Scattered Flow } \\
\text { Grade } 3 \text { continuous flow** }\end{array}$ & $\begin{array}{c}3 \\
1 \\
12 \\
27\end{array}$ & $\begin{array}{c}6.9 \\
2.3 \\
27.9 \\
62.7\end{array}$ \\
\hline 2. & $\begin{array}{l}\text { Pattern of Vascularity** } \\
\text { Arborizing pattern }\end{array}$ & 26 & 60.4 \\
\hline & $\begin{array}{l}\text { TABLE 5: COLOR, DUPLEX AND PC } \\
\text { FEATURES OF GALLBLADDER }\end{array}$ & $\begin{array}{l}\text { DOF } \\
\text { INOI }\end{array}$ & \\
\hline
\end{tabular}

Color, Duplex and Power Doppler Features of Gallbladder Carcinoma: 93\% of the gallbladder carcinomas were vascular with majority of them showing Grade 2 vascularity on CDFI. All the tumor vessels had a peak systolic velocity $>40 \mathrm{~cm} / \mathrm{s}$.

Power Doppler showed more Doppler signals than color Doppler in gallbladder carcinomas. In 9 cases, vascularity which was Graded 1 on color Doppler shifted to Grade 2 on Power Doppler. Further, 10 cases of Grade 2 improved to grade 3 vascularity on power Doppler. Arborizing pattern was seen in 26 cases (60\%) on power Doppler imaging.

\begin{tabular}{|c|c|c|}
\hline Cholelithiasis & No. of Patients & Percentage (\%) \\
\hline Gallstones detected & 30 & 70 \\
\hline - Gallstones embedded in mass & 24 & 56 \\
\hline - Gall stones in lumen of gall bladder (exclusively) & 6 & 14 \\
\hline
\end{tabular}

On ultrasonography associated calculus with gallbladder carcinoma are seen in 30 cases accounting for $(70 \%)$ of cases.

Calculus is seen more commonly embedded in mass, seen in 24 cases, accounting for (80\%) of cases in which calculus is seen. Calculus exclusively seen in the lumen of gallbladder in 6 cases (20\%).

DISCUSSION: In our study a total of 10,424 patients were evaluated with grey scale Ultrasonography, out of these 54 patients were evaluated with grey scale sonography, color and duplex Doppler. In our study ultrasound was able to correctly diagnose all the 54 cases of gallbladder mass lesions, confirmed by surgery/histopathology/FNAC, suggestive of specificity of sonography of $100 \%$ in diagnosing the gallbladder mass lesions.

In our study, Carcinoma was the commonest type (79.5\%) of mass lesion encountered in gallbladder. Metastasis accounted for (1.9\%) cases. All the benign masses in total accounted for remaining (18.6\%) of gallbladder mass lesions. Gallbladder polyps are most common among the benign lesions accounting for $(9.3 \%)$ cases, with mucocele second most common accounting for 


\section{ORIGNAL ARTICLE}

(7.4\%) of cases and porcelain gallbladder accounting for $(1.9 \%)$ of masses. In our study group youngest patient was 12 year old male presented with mucocele. Oldest patient in our study was 68 year old female presented with gallbladder carcinoma. Maximum numbers of cases were encountered in the age group of 50-60 years.

Patients above the age of 40 years account for $34 / 43,(80 \%)$ cases of gallbladder carcinoma and $74 \%$ of all the mass lesions. $76 \%$ of overall GB mass lesions were encountered in females, showing clear female preponderance, with female to male ratio 3:1.7. Most cases in our study presented with pain in abdomen, mostly in right hypochondrium accounting for 37/54 (58\%) cases. Most common sign encountered in our study is lump in right hypochondrium accounting for 35/54 (64\%) of all GB masses. Three cases of polyps were diagnosed incidentally on ultrasonography, for complaints unrelated to GB masses. Our findings are in concordance with the references. ${ }^{14,15} 5$ cases of gallbladder polyp were observed, 3 cases were observed incidentally on sonography, other common presentation was pain. 4 cases of mucocele were observed; mucocele represented the youngest case in our study.

One case of porcelain gallbladder was observed in our study. No vascular signal were demonstrated on CDFI and PDI. One case of metastasis to gallbladder was observed. On sonography it appeared as focal thickening of wall with echogenic nodule in the wall of gallbladder. On CDFI and PDI the lesion revealed to be avascular. Carcinoma gallbladder was the most common type of mass lesion of gallbladder encountered in our study, accounted for (79.5\%) of all cases. Among malignancies carcinoma was the only lesion except for 1 case $(1.9 \%)$ of metastasis. Carcinoma accounted for $43 / 44(98 \%)$ of all malignancies.

Females accounted for (77\%) of cases of carcinoma, suggestive of female preponderance with female/male ratio of 2.3:1.

In our study $93 \%$ of the gallbladder carcinomas were vascular with majority of them showing grade 2 vascularity on CDFI. Grade 2 or more signal seen in $70 \%$ of patients. Similar results were reported by ref 15 , who found abnormal color signal in $81 \%$ of cases.

Power Doppler imaging showed greater sensitivity than CDFI. In addition PDI is not subjected to aliasing and is angle independent. Power Doppler showed vascularity in $93 \%$ of cases. PDI showed grade 2 or more signal in $90 \%$ of cases, $60 \%$ of cases demonstrated arborizing pattern on PDI. Thus PD appeared superior to CDFI in our study. All the tumor vessels had a peak systolic velocity $>40$ $\mathrm{cm} / \mathrm{s}$.

Associated calculus in gallbladder carcinoma were seen in (70\%) of cases, seen on sonography. Calculi are seen as echogenic foci with posterior acoustic shadowing. Calculus is seen more commonly embedded in mass, seen in 24 cases, accounting for ( $80 \%)$ of cases in which calculus is seen. Calculi were exclusively seen in the lumen of gallbladder in 6 cases, (20\%).

CONCLUSION: In our study conducted for duration of 1 year in J.A. Group of Hospital and G.R. Medical College, Gwalior which serves a good proportion of population of M.P. and adjoining areas of U.P. and Rajasthan, 6.6\% (43) patients had gallbladder Mass 0.7\% (5) had gallbladder polyp, 0.6\% (4) had Mucocele of gallbladder, $0.1 \%$ (1) patient had porcelain gallbladder and $0.1 \%$ (1) showing gallbladder metastasis.

The present study concludes that ultrasonography is a powerful, readily available and cost effective tool in the diagnosis of Gallbladder Pathology. Grey scale ultrasonography, along with color 


\section{ORIGNAL ARTICLE}

Doppler imaging and power Doppler should be used as a first line investigation in the evaluation of gallbladder mass lesions. The lesions diagnosed as benign on ultrasonography require no further radiological evaluation. The lesions which are diagnosed as malignant on ultrasonography should be subjected to the further evaluation by Histopathology/FNAC to decide the proper course of further management of patient.

\section{REFERENCES:}

1. Piehler JM, Crichlow RW. Primary carcinoma of the gallbladder. Surg Gynecol Obstet 1978; 147: 929-942.

2. Serra I, Yamamoto M, Calvo A et al. Association of chilli pepper consumption, low socioeconomic status and long standing gall stone with gall bladder cancer in Chilean population .Int J Cancer 2002:102:406-411.

3. Strom BL, Soloway RD, Rios-Dalenz JL et al. Risk factor for gall bladder cancer- An International collaborative case control study .Cancer 1995:76:1747-1757.

4. Sunil Seth , A. Bedford. Primary gall bladder cancer: recognition of risk factor and the role of prophylactic cholecystectomy. Am J Gastro.2000.

5. Diehl AK, Sugrek NJ, Todd KH. Clinical evaluation for gallstone disease usefulness of symptoms and sign of diagnosis. Gastroentrol J 1990-50(4) 172-4.

6. Shukla VK, Khandelwal C, Roy S.K, Vaidya MP. Primary carcinoma of gall bladder: a review of 16 year period at the university hospital. J Surg Oncol 1985.28:32-5.

7. Moerman CJ, Bueno-de-Mesquta, Hbas, Runio ,S. Smoking, alcohol consumption and the risk of cancer of the biliary tract. Eur. J of Cancer Prevention Vol.3- issue 5.Sept.1994.

8. Axelord L. Typhoid cholecystitis and gall bladder, carcinoma after interval of 67 years. JAMA 1963:40:429.

9. Keush CT. Salmonellosis in Harrison principle of Internal Medicine Edn, Wilson JD .Brounwald E. Isselbacher KJ, Peterdorf RG, Martin JS .Fauci AS, Root RK (Eds). 1991. McGraw Hill, New York pp .609-613.

10. Welton JC, Marr JS, Friedman SM. Associated between hepatobiliary cancer and typhoid carrier state. Lancet 1979; I :491-4.

11. E W Benbow. Xanthogranulomatous cholecystitis associated with carcinoma of the gall bladder. Postgraduate Medical Journal 1989,65,528-53.

12. Shukla VK, Tiwari SC, Roy SK. Biliary bile acids in cholelithiasis and carcinoma of the gall bladder. Eur J Cancer Prev 1993; 2:155-160.

13. Lowenfles AB, Walker AM, Althaus DP, Townsend G, Domell OF. Gall stone growth size and risk of gallbladder cancer; an Interracial study. Int Epedimol 1989 18;50.4.

14. M Barbhuiya, T Singh, S Gupta, B Shrivastav, P Tiwari. Incidence of gall bladder cancer in rural and semiurban population of North central India. The Internal journal of epidemiology.2008 volume 7 number 2 .

15. Abhishek Vijayakumar, Avinash Vijayakumar, Vijayaraj Patil, M N Mallikaarjuna and B S Shivaswamy. ISRN Radiology volume 2013, Article ID 239424

16. Hirooka Y, Naithoh Y, Goto H, Furukawa T,Lto A Hayakawa T. Differential Diagnosis of Gall bladder masses using color ultrasonography. Journal of Gastroenterology and Hepatology 1996;11:840-846. 


\section{ORIGNAL ARTICLE}

\section{MUCOCELE:}



Fig. 1: Image shows Mucocele of Gall Bladder

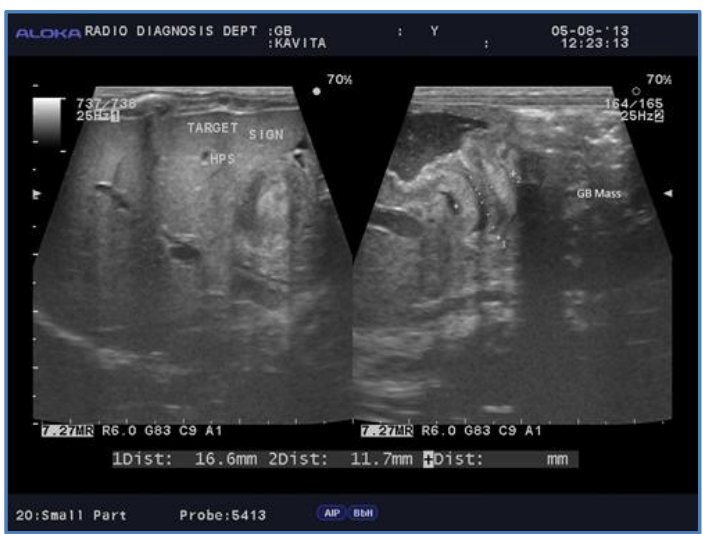

Fig. 2: Image shows Gall Bladder Mass with infiltration of liver

\section{GALL BLADDER MASS:}



Fig. 3: Image shows Gall Bladder Mass 


\section{ORIGNAL ARTICLE}

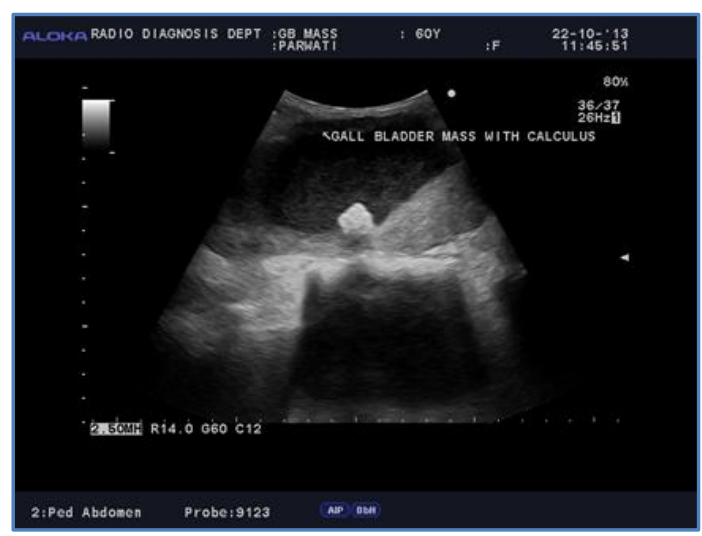

Fig. 4: Image shows Gall Bladder Mass with calculus

POLYP:

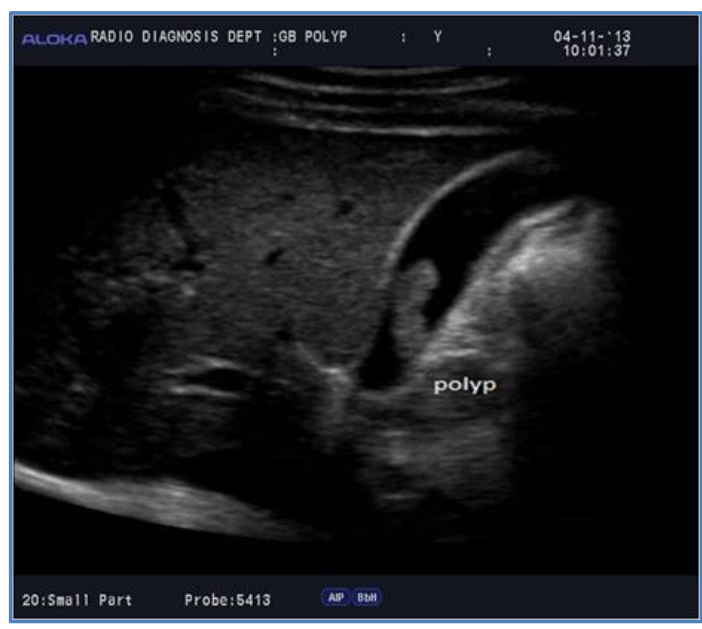

Fig. 5: Image shows solitary Gall Bladder polyp on USG No posterior acoustic shadowing


Fig. 6: Image shows real vascularity in gall bladder polyp 


\section{ORIGNAL ARTICLE}

\section{POLYP:}
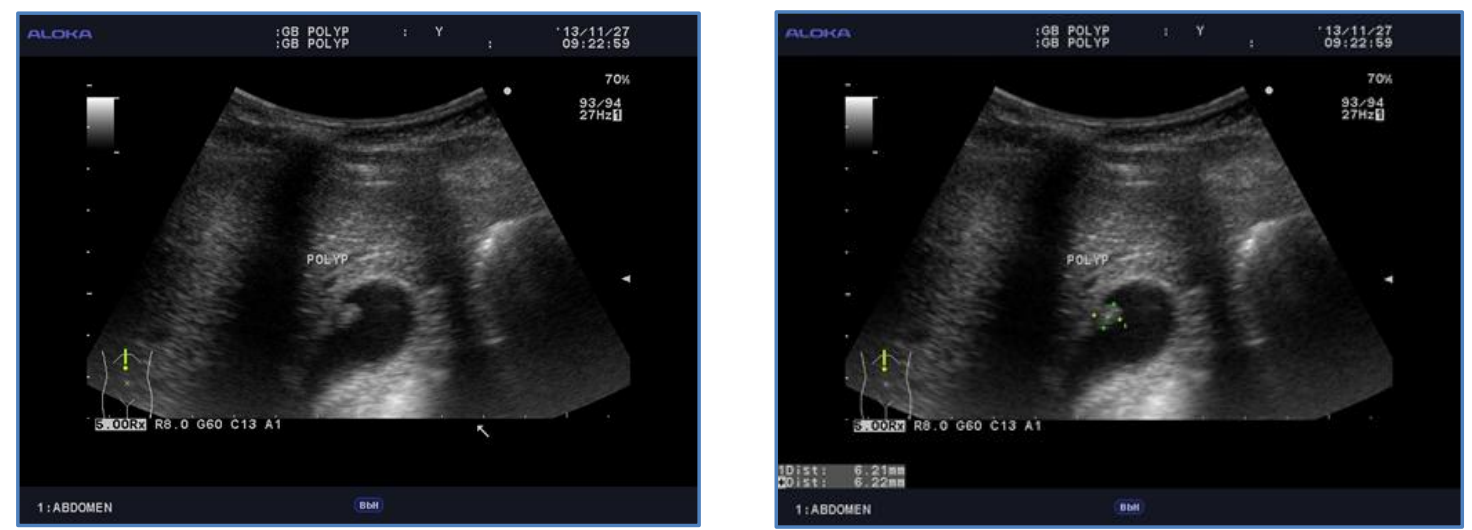

Fig. 7: Images show solitary Gall Bladder Polpy on USG No Posterior Acoustic shadowing
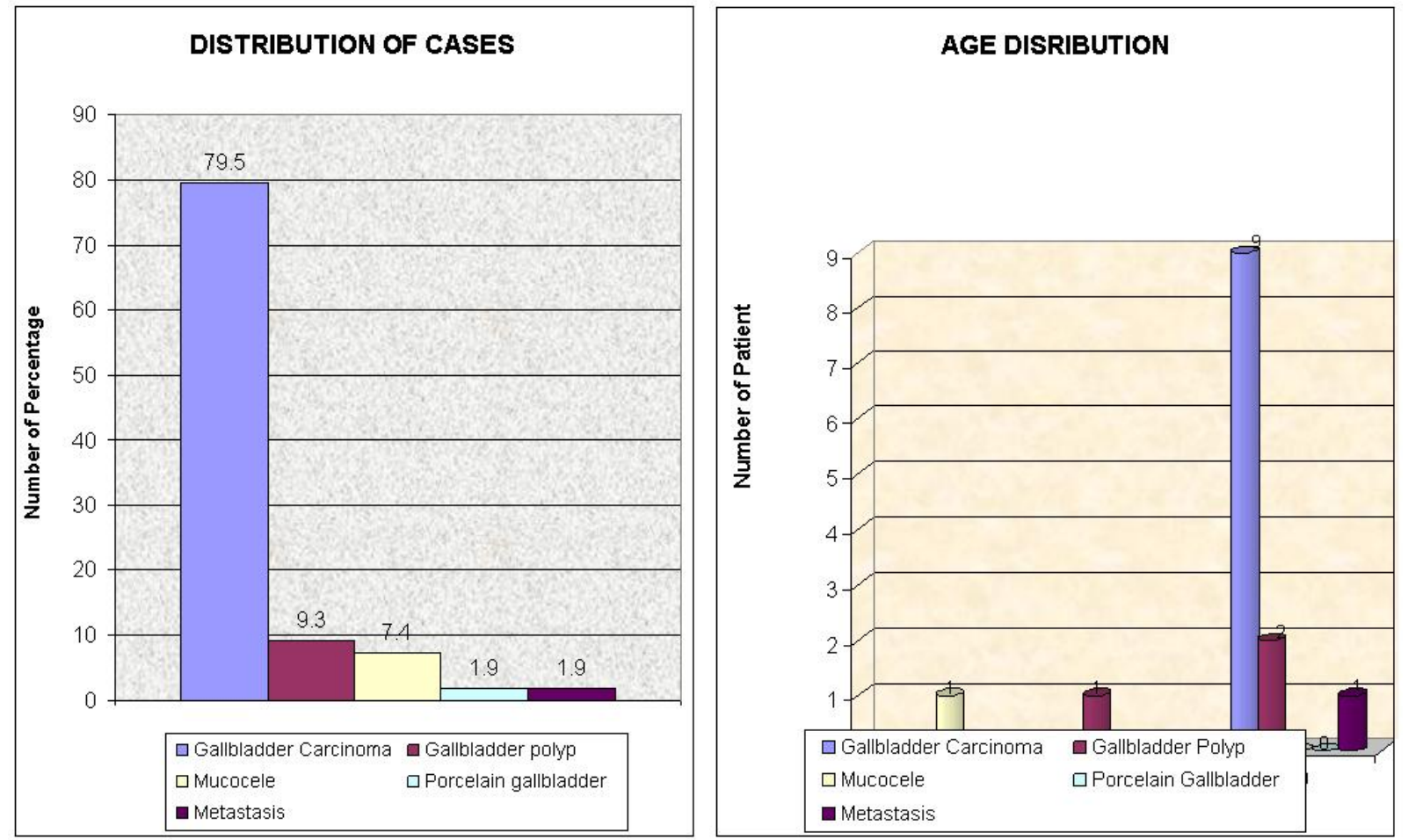


\section{ORIGNAL ARTICLE}

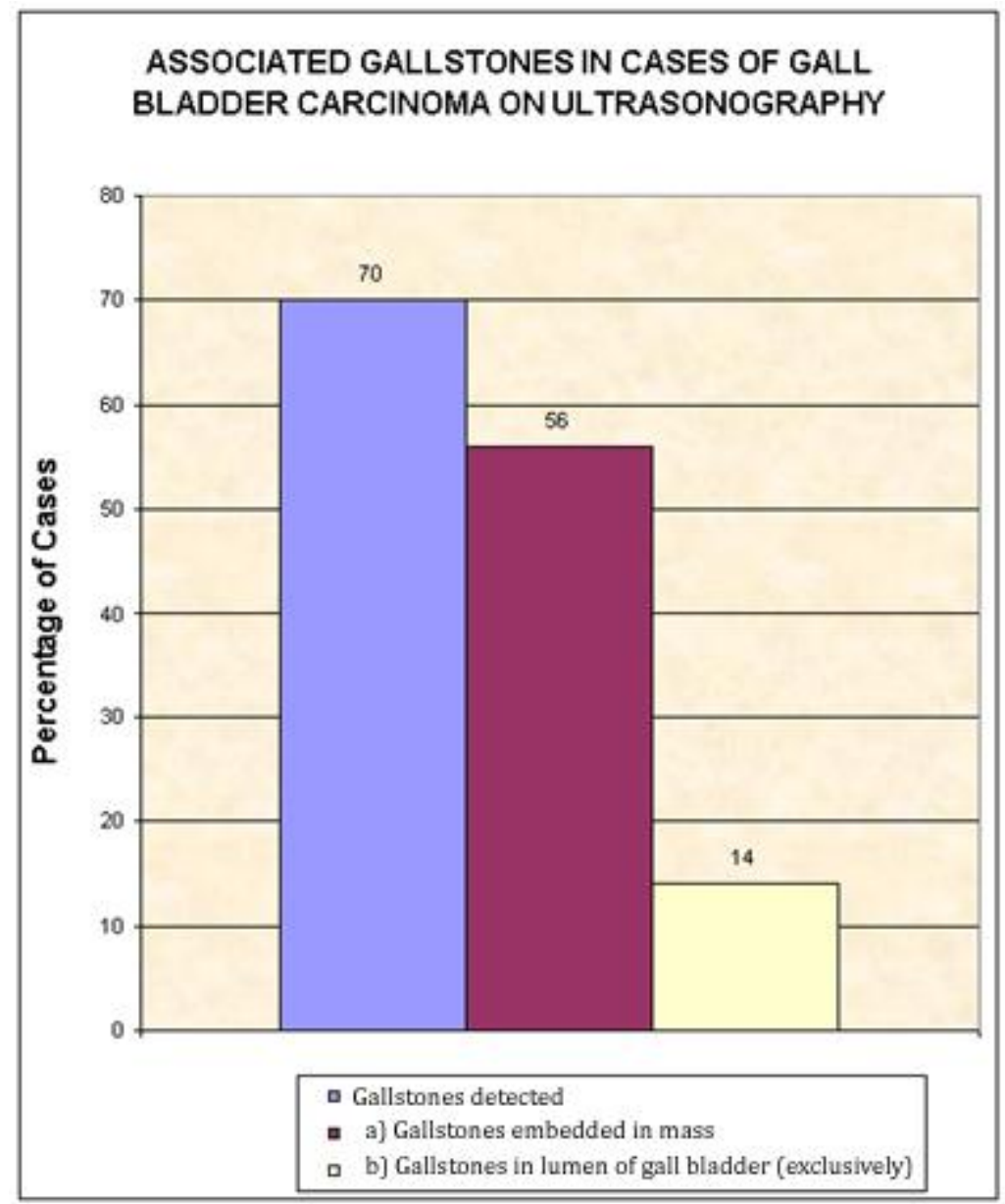

\section{AUTHORS:}

1. J. S. Sikarwar

2. Rashmi Singh

3. Vrashbhan Ahirwar

4. Harish Bhujade

5. Shilpi Muchhoria

\section{PARTICULARS OF CONTRIBUTORS:}

1. Associate Professor and Head, Department of Radiodiagnosis, G. R. Medical College and J.A. Hospital, Gwalior.

2. Resident, Department of Radiodiagnosis, G.R. Medical College and J.A. Hospital, Gwalior.

3. Resident, Department of Radiodiagnosis, G.R. Medical College and J.A. Hospital, Gwalior.
4. Resident, Department of Radiodiagnosis, G.R. Medical College and J.A. Hospital, Gwalior.

5. Resident, Department of Radiodiagnosis, G.R. Medical College and J.A. Hospital, Gwalior.

\section{NAME ADDRESS EMAIL ID OF THE CORRESPONDING AUTHOR:}

Dr. Rashmi Singh,

C/o. Rajendra Singh Kushwaha,

A-06, Vijay Nagar,

AAmkho Lashkar,

Gwalior, PIN: 474001.

E-mail: rashmi.singh0302@gmail.com

Date of Submission: 22/01/2014.

Date of Peer Review: 23/01/2014.

Date of Acceptance: 27/01/2014.

Date of Publishing: 25/02/2014. 